\title{
Effect of Dy doping on magnetostrictive and mechanical properties of $\mathrm{Fe}_{83} \mathrm{Ga}_{17}$ alloy
}

\author{
Xin-lei Wang', *Yuan Liu', ${ }^{1,}$ Xiang Chen ${ }^{1,2}$, Hua-wei Zhang', ${ }^{1,}$ and Yan-xiang Li' ${ }^{1,2}$ \\ 1. School of Materials Science and Engineering, Tsinghua University, Beijing 100084, China \\ 2. Key Laboratory for Advanced Materials Processing Technology, MOE, China
}

\begin{abstract}
Fe}_{83} \mathrm{Ga}_{17}$ alloy is a kind of promising magnetostrictive alloys with high magnetostrictive properties and a low saturation magnetic field. As-cast $\mathrm{Fe}_{83} \mathrm{Ga}_{17} \mathrm{Dy}_{x}(x=0,0.05,0.1,0.2,0.4)$ polycrystalline alloys were prepared by arc melting. Effect of Dy doping on the microstructure, magnetostrictive and mechanical properties of as-cast $\mathrm{Fe}_{83} \mathrm{Ga}_{17}$ alloy was investigated. Results show that Dy-doped alloys exhibit a dual-phase structure containing the $\mathrm{A} 2$ matrix and Dy-rich precipitates $\left(\mathrm{Fe}_{56} \mathrm{Ga}_{34} \mathrm{Dy}{ }_{10}\right)$. Both magnetostriction and mechanical properties of $\mathrm{Fe}_{83} \mathrm{Ga}_{17}$ alloys are improved by Dy doping. A small amount of Dy addition $(x=0.2)$ significantly causes $\mathrm{Fe}_{83} \mathrm{Ga}_{17}$ alloy to transform from typical brittle material (fracture strain $\varepsilon<1 \%$ ) to plastic material $(\varepsilon \approx 11 \%$ ). Correspondingly, the fracture mode transforms from intergranular fracture to dimple fracture. At the same time, the ultimate tensile strength and the magnetostriction rise up to $209 \mathrm{MPa}$ and $64 \mathrm{ppm}$, respectively. Dy-rich precipitates disperse along the grain boundries and inside the grains, which plays an important role in the grain refinement and solution strengthening, and therefore, contribute to the enhancement of mechanical properties of the alloy. The improvement of magnetostriction could be attributed to the large lattice distortion induced by Dy atoms entering into the A2 matrix. Doping Dy into Fe-Ga alloys provides an effective solution to the brittleness in their applications.
\end{abstract}

Key words: Fe-Ga alloys; Dy doping; mechanical properties; magnetostriction
CLC numbers: TG143
Document code: A

Article ID: 1672-6421(2020)03-198-08

M agnetostriction is generally considered as the change in dimension of materials under an applied external magnetic field. Magnetostrictive materials have attracted widespread attention due to their utilization in actuators, sensors, transducers, microelectromechanical systems and energy harvesting ${ }^{[1,2]}$. Among various magnetostrictive materials, the Tb-Dy-Fe alloys (known as Terfenol-D) and Fe-Ga alloys (known as Galfenol) are the two most promising materials. Compared to Terfenol-D, Fe-Ga alloys exhibit good combination advantages: (i) low saturation magnetic field $(\sim 100$ Oe); (ii) moderate magnetostriction ( $400 \mathrm{ppm})$; (iii) good mechanical properties; (iv) low cost; (v) high Curie temperature $\left(T_{\mathrm{c}}>650{ }^{\circ} \mathrm{C}\right){ }^{[3-7]}$. Therefore, since 2000 , many studies on microstructure, magnetostrictive and mechanical properties of Fe-Ga alloys have been carried out.

Fe-Ga single crystal alloys exhibit good robustness,

\section{*Yuan Liu}

Male, born in 1974, Ph.D., Associate Professor. His research interests mainly focus on porous materials, solidification theory and magnetostrictive materials.

E-mail: yuanliu@tsinghua.edu.cn

Received: 2020-01-19; Accepted: 2020-04-14 toughness and excellent magnetostriction, but their industrial applications are limited due to the high preparation cost ${ }^{[3,8]}$. However, polycrystalline Fe-Ga alloys, which can be prepared relatively easily, demonstrate the drawbacks of low magnetostriction and intrinsic brittleness ${ }^{[4,9]}$. Besides, the eddy current losses induced by the high conductivity of $\mathrm{Fe}-\mathrm{Ga}$ alloys limit their operation at high frequencies. Rolling them into thin sheets has been confirmed to be an economical and effective way to reduce the eddy current losses ${ }^{[10-12]}$. Therefore, obtaining excellent ductility is very important for rolling polycrystalline Fe-Ga alloys. In order to solve these issues, an effective method of alloying element addition to Fe-Ga alloys has been much studied. On the one hand, much work has been done to improve the magnetostriction by adding main group elements such as $\mathrm{Be}, \mathrm{B}, \mathrm{C}, \mathrm{N}, \mathrm{Al}$, $\mathrm{Si}, \mathrm{Ge}, \mathrm{Sn}{ }^{[10,12-18]}$; $3 \mathrm{~d}$ and $4 \mathrm{~d}$ transition elements such as $\mathrm{V}, \mathrm{Cr}, \mathrm{Mn}, \mathrm{Co}, \mathrm{Ni}, \mathrm{Zn}, \mathrm{Nb}, \mathrm{Mo}, \mathrm{Rh}^{[9,11,14,17,19-21]}$; and rare earth elements such as Y, La, Ce, Sm, Tb, Dy, Er ${ }^{[22-31]}$. Among the above elements, interstitial elements B, C, and $\mathrm{N}$ slightly increase the magnetostriction, but trace doping with rare-earth elements can greatly enhance the magnetostriction of $\mathrm{Fe}-\mathrm{Ga}$ alloys due to the strong localized magnetocrystalline anisotropy. The other 
elements cannot significantly improve the magnetostriction. On the other hand, in order to enhance the mechanical properties, great efforts has been made by adding alloying elements such as $\mathrm{B}, \mathrm{C}, \mathrm{Al}, \mathrm{V}, \mathrm{Cr}, \mathrm{Mo}, \mathrm{Mn}, \mathrm{Nb}^{[9-12,17,32]}$ or carbide precipitates such as $X-\mathrm{C}(X=\mathrm{Zr}, \mathrm{Nb}, \mathrm{Mo}, \mathrm{Ta})^{[33-37]}$. This method is effective to enhance the mechanical properties, but it cannot significantly improve the magnetostrictive performance. Recent studies have found that the small addition of rare-earth elements $\mathrm{Y}$ and $\mathrm{Tb}$ could significantly enhance the magnetostrictive and mechanical properties of the as-cast $\mathrm{Fe}-\mathrm{Ga}$ polycrystalline alloys simultaneously ${ }^{[38,39]}$. A small amount of Y (0.16at.\%) increased the tensile strength of as-cast $\mathrm{Fe}_{83} \mathrm{Ga}_{17}$ alloys to $674 \mathrm{MPa}$ and improved the ductility with elongation of $4.2 \%$ at room temperature ${ }^{[38]}$. The improved ultimate tensile strength $(595 \pm$ $10 \mathrm{MPa})$ and fracture strain $(3.5 \pm 0.1 \%)$ were obtained with the increased magnetostriction of $105 \pm 9 \mathrm{ppm}$ in the $\mathrm{Tb}$-doped $\mathrm{Fe}$ Ga alloys ${ }^{[39]}$. Even so, there remains a strong requirement for further improvement in ductility of polycrystalline Fe-Ga alloys with relatively good strength and magnetostriction.

Based on the above analysis, the rare-earth element Dy was added into the $\mathrm{Fe}_{83} \mathrm{Ga}_{17}$ alloy, aiming to improve both the magnetostriction and ductility. In this work, the microstructure, magnetostrictive and mechanical properties of as-cast $\mathrm{Fe}_{83} \mathrm{Ga}_{17} \mathrm{Dy}_{x}(0 \leq x \leq 0.4)$ polycrystalline alloys were investigated.

\section{Experimental materials and methods}

High-purity starting elements iron, gallium and dysprosium were arc-melted four times in preparation of master alloys with nominal composition of $\mathrm{Fe}_{83} \mathrm{Ga}_{17} \mathrm{Dy}_{x}(x=0,0.05,0.1,0.2,0.4)$. The ingots with a diameter of $28 \mathrm{~mm}$ were annealed at 1,373 $\mathrm{K}$ for $1 \mathrm{~h}$ and then $1,073 \mathrm{~K}$ for $2 \mathrm{~h}$ followed by quenching in water. Phase composition and crystal structure were determined by X-ray diffraction (XRD) on a D8-Advance diffraction meter $(\mathrm{Cu} \mathrm{K} \alpha$ radiation, $\lambda=1.5418 \AA$ and scanning speeding of $\left.6^{\circ} \cdot \mathrm{min}^{-1}\right)$ at room temperature. Static tensile tests were carried out using an Instron-1041testing machine in a constant velocity of $1 \times 10^{-4} \mathrm{~s}^{-1}$ at room temperature. Three tensile samples with a gauge dimension of $8 \mathrm{~mm} \times 2 \mathrm{~mm} \times 1 \mathrm{~mm}$ were cut from the center of each ingot. The microstructure, chemical composition, and fracture morphology of the tensile sample were characterized by field emission scanning electron microscopy (FESEM) (Zeiss MERLIN-VP-COMPACT) equipped with an energy dispersive X-ray Spectroscopy (EDS) (Oxford INCA) analyzer. The static measurement of magnetostriction was tested by the standard strain gauge with the sample size of $10 \mathrm{~mm} \times 6 \mathrm{~mm} \times 6 \mathrm{~mm}$. Magnetization hysteresis loops were measured by using a vibrating sample magnetometer (VSM) at room temperature in magnetic fields up to $\pm 0.9 \mathrm{~T}$.

\section{Results and discussion}

\subsection{Microstructure of $\mathrm{Fe}_{83} \mathrm{Ga}_{17} \mathrm{Dy}_{x}(x=0,0.05$, $0.1,0.2,0.4$ ) alloys}

Figure 1 shows back scattered electron (BSE) images of $\mathrm{Fe}_{83} \mathrm{Ga}_{17} \mathrm{Dy}_{x}(x=0,0.05,0.10 .2,0.4)$ alloys. In the un-doped alloy $(x=0)$, the single-phase structure with coarse equiaxed grains is observed with an average size of $\sim 570 \mu \mathrm{m}$. In the Dy-doped alloys, the precipitates of a secondary phase, which are bright spheres and rods, can be seen. The amount of precipitates gradually increases with an increase in dopant content of Dy. The relationship between grain size and Dy content is summarized in Fig. 2. It is obvious that doping Dy into $\mathrm{Fe}-\mathrm{Ga}$ alloys leads to a significant grain refinement from $\sim 200 \mu \mathrm{m}$ for $x=0.05$ to $\sim 40 \mu \mathrm{m}$ for $x=0.4$. For $x=0.05$ and 0.1 , the homogeneous equiaxed grains with straight boundaries
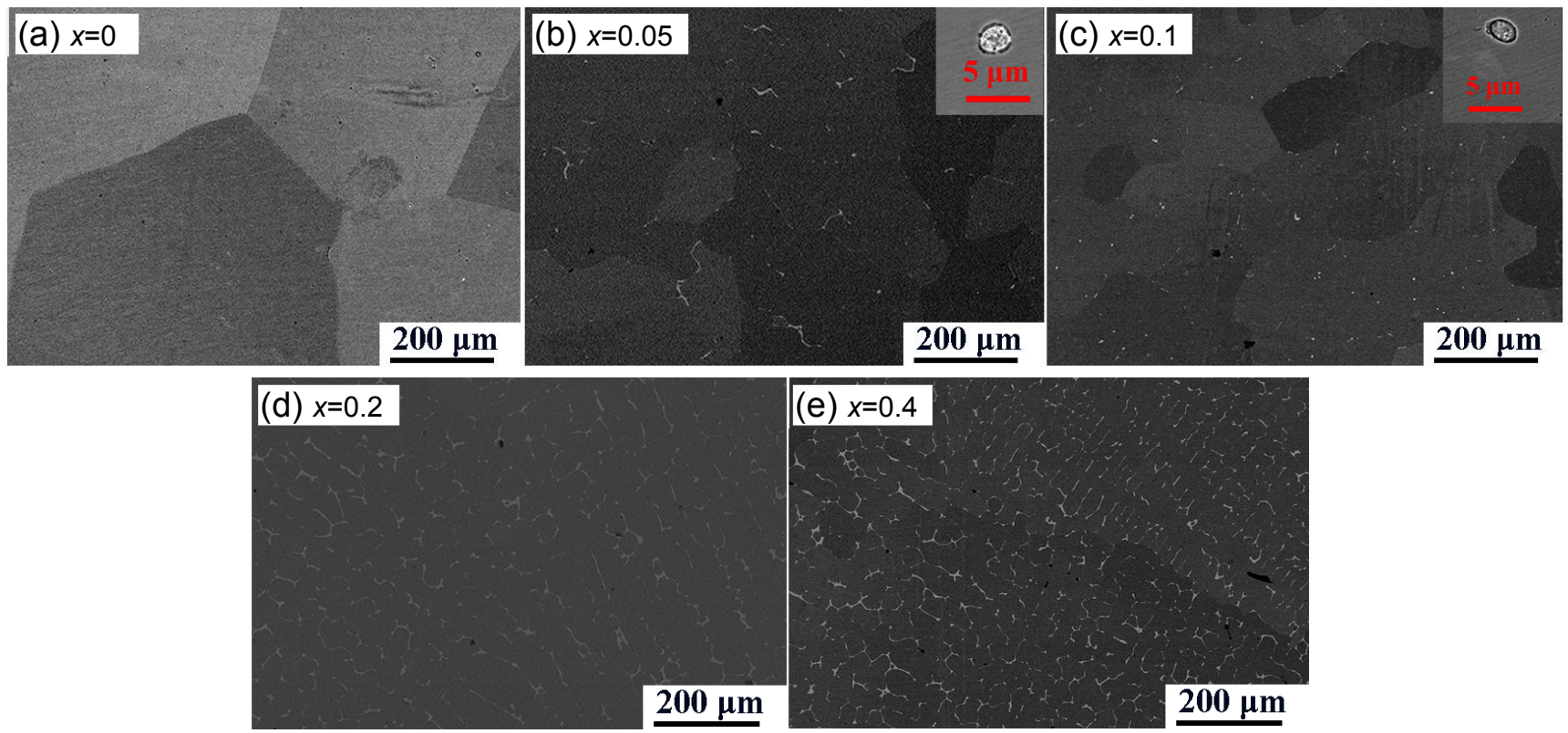

Fig. 1: Back scattered electron images of $\mathrm{Fe}_{83} \mathrm{Ga}_{17} \mathrm{Dy}_{x}(x=0,0.05,0.1,0.2,0.4)$ alloys. The insets are magnifications of the spheres 


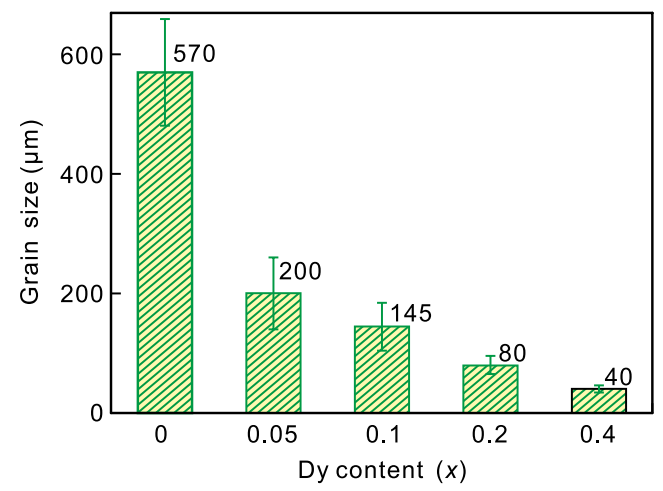

Fig. 2: Dy content dependence of grain size of $\mathrm{Fe}_{83} \mathrm{Ga}_{17} \mathrm{Dy}_{x}$ $(x=0,0.05,0.1,0.2,0.4)$ alloys

can be observed. The spherical precipitates mainly disperse inside the grains with an average size of $\sim 3 \mu \mathrm{m}$, and the rodlike precipitates disperse at the grain boundaries, as shown in Fig. 1 (b and c). When $x$ increases to 0.2 and 0.4 , the distribution pattern of the secondary phase changes from dispersion phase to continuous network, and the volume fraction of the precipitates increases to $\sim 1.7 \%$ and $\sim 2.9 \%$, respectively. The size of the rod-like precipitates dispersed at the grain boundaries is about
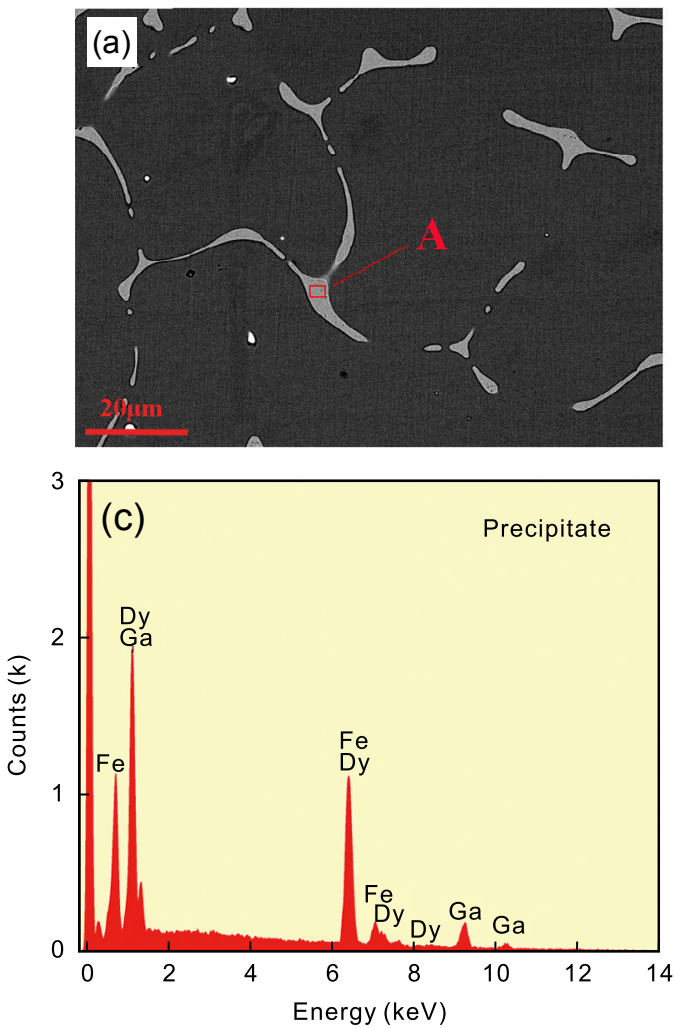

$2 \mu \mathrm{m} \times 30 \mu \mathrm{m}$. In addition, the grains are further refined and the precipitates mainly exist at the grain boundaries. The precipitation of the second phase along the grain boundaries and inside the grains plays an important role in the grain refinement, and previous studies on $\mathrm{Fe}-\mathrm{Ga}$ based alloys have shown similar characteristics ${ }^{[24,28,33,39]}$. The formation of the second phase in the $\mathrm{Fe}_{83} \mathrm{Ga}_{17} \mathrm{Dy}_{\mathrm{x}}$ alloys is attributed to the difference in the atomic size of Fe, Ga, and Dy. The atomic size of Dy $(177 \mathrm{pm})$ is significantly larger than that of Fe (127 pm) and Ga (140 pm), which results in a low solid solubility of Dy in the matrix. Therefore, element Dy mainly exists in the precipitates. Some previous studies have observed this characteristic dualphase structure in other rare-earth-doped Fe-Ga alloys (such as $\mathrm{Tb}, \mathrm{Sm}, \mathrm{Y}, \mathrm{Ce}, \mathrm{Er})^{[25,27,28,31,38,40]}$, and it is believed to be beneficial for improving the magnetostrictive properties of this material system.

Figure 3 shows the SEM morphology of the $\mathrm{Fe}_{83} \mathrm{Ga}_{17} \mathrm{Dy}_{0.4}$ alloy and corresponding EDS for grain boundary (Fig. 3c) and grain (Fig. 3d). It can be found that the matrix is mainly composed of $\mathrm{Fe}$ and $\mathrm{Ga}$, while the precipitates contain relatively high percentage of Dy, besides Fe and Ga. Quantitative analysis results of EDS are given in Table 1. Compared with the matrix
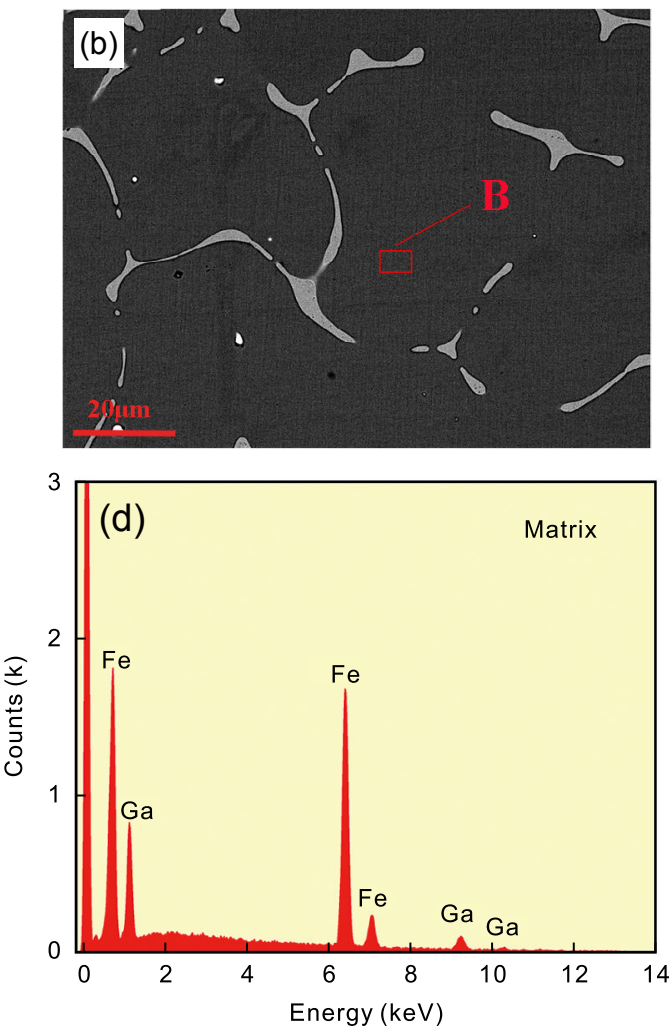

Fig. 3: SEM images of $\mathrm{Fe}_{83} \mathrm{Ga}_{17} \mathrm{Dy}_{0.4}$ alloy (a, b), corresponding EDS for the precipitate region marked as "A" (c), and the matrix region marked as " $B$ " (d)

Table 1: EDS results of precipitates and matrix for Fe-Ga-Dy alloys (at.\%)

\begin{tabular}{cccc} 
& $\mathrm{Fe}$ & $\mathrm{Ga}$ & $\mathrm{Dy}$ \\
\hline Matrix & 83.22 & 16.78 & - \\
Precipitates & 56.23 & 33.57 & 10.20 \\
\hline
\end{tabular}

(Fe 83.22at.\%, Ga 16.78at.\%), the precipitates (Fe 56.23at.\%, Ga 33.57at.\%, Dy 10.20at.\%) are confirmed to be a Dy-rich phase, indicating that Dy atoms accumulate more at the grain boundaries.

Figure 4 shows the XRD patterns of the $\mathrm{Fe}_{83} \mathrm{Ga}_{17} \mathrm{Dy}_{x}(x=0$, $0.05,0.1,0.2,0.4$ ) alloys at room temperature, and the inset is a magnification of the black box. Three main diffraction 


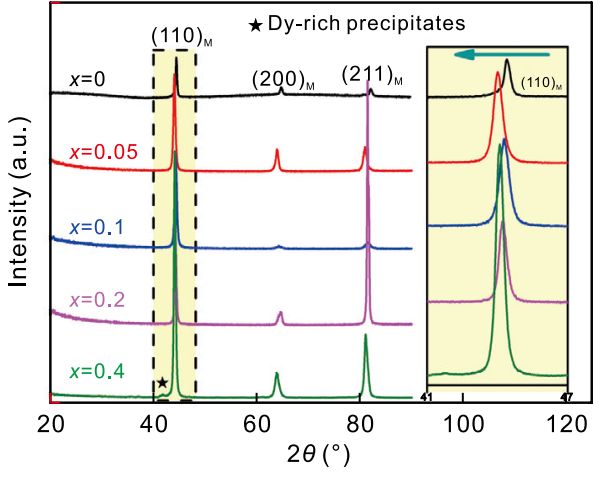

Fig. 4: XRD patterns of $\mathrm{Fe}_{83} \mathrm{Ga}_{17} \mathrm{Dy}_{x}(x=0,0.05,0.1,0.2,0.4)$ alloys at room temperature. The right inset is a magnification of the black dotted line box

peaks are observed for all the alloys, which are indexed as (110), (200) and (211) for the body-centered cubic (bcc) structure. This illustrates that the matrix of all the Dy-doped alloys possesses the same bcc structure as that of the binary $\mathrm{Fe}_{83} \mathrm{Ga}_{17}$ alloy. Combined with previous studies ${ }^{[26,28]}$, the matrix should be the A2 solid solution phase. For the $\mathrm{Fe}_{83} \mathrm{Ga}_{17} \mathrm{Dy}_{0.4}$ alloy, there is an unknown diffraction peak at $2 \theta \approx 41.7^{\circ}$ marked by a star, which is thought to come from the Dy-rich precipitates. For the alloys with $x=0.05$, 0.1 and 0.2 , the amount of precipitates is too small to be detected by XRD. In general, the above XRD results are in agreement with the back scattered electron images shown in Fig. 1.

\subsection{Mechanical properties of $\mathrm{Fe}_{83} \mathrm{Ga}_{17} \mathrm{Dy}_{\mathrm{x}}$ alloys}

Figure 5(a) shows the tensile stress-strain curves of $\mathrm{Fe}_{83} \mathrm{Ga}_{17} \mathrm{Dy}$ $(x=0,0.05,0.1,0.2,0.4)$ alloys at room temperature. Dy content $x$ dependence of ultimate tensile strength and fracture strain is summarized in Fig. 5(b), and the specific values are shown in Table 2. Several tensile tests were carried out for each alloy to ensure accuracy of the data. Dy doping improved the mechanical properties of $\mathrm{Fe}_{83} \mathrm{Ga}_{17}$ alloy. For the binary $\mathrm{Fe}_{83} \mathrm{Ga}_{17}$ alloy, there is only typical elastic deformation. The ultimate tensile strength of $139 \pm 30 \mathrm{MPa}$ and the corresponding facture strain of $0.24 \pm 0.01 \%$ are obtained in the tensile testing. After doping Dy, the ultimate tensile strength and fracture strain increase in different extent with the formation of precipitates. For the $x=0.05$ specimen, the ultimate tensile strength increases to a maximum of $408 \pm 15 \mathrm{MPa}$, which is three times as large as Dy-free $\mathrm{Fe}_{83} \mathrm{Ga}_{17}$ alloy, and the corresponding fracture strain is $0.91 \pm 0.03 \%$. When $x$ increases to 0.1 , the specimen begins to yield, and an ultimate tensile strength of $390 \pm 10 \mathrm{MPa}$ is obtained with the dramatically increased fracture strain of $2.73 \pm 0.06 \%$. When Dy addition continues to increase, the ultimate tensile strength of the specimens falls significantly to $209 \pm 7 \mathrm{MPa}$ for $x=0.2$ and $186 \pm 9 \mathrm{MPa}$ for $x=0.4$, but the fracture strain increases remarkably to a maximum of $11.03 \pm 0.21 \%$ for $x=0.2$ and $9.94 \pm 0.04 \%$ for $x=0.4$, which indicates that excellent ductility can be obtained in Fe-Ga alloy with Dy doping. The fracture strains of the Dy-doped $\mathrm{Fe}_{83} \mathrm{Ga}_{17}$ alloys are significantly further improved, compared to $\mathrm{Y}$ and $\mathrm{Tb}$ doped Fe-Ga alloys ${ }^{[38,39]}$. Besides, it is noteworthy that the $x=0.2$ and 0.4 specimens exhibit an extremely wider yield platform, compared to the $x=0.1$ specimen, which indicates the appearance of a large amount of plastic deformation and great fracture strains in these alloys. Overall, a very small addition of Dy can greatly enhance the ultimate tensile strength and also slightly improve the ductility with $0<x \leq 0.1$. Further addition of Dy can significantly
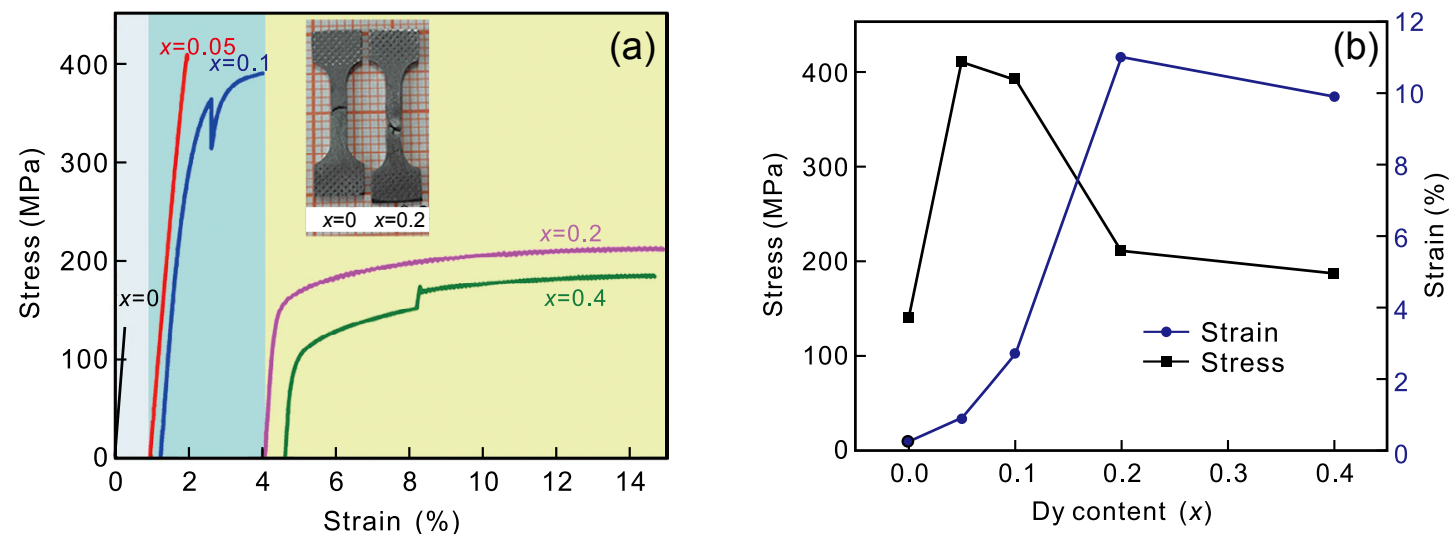

Fig. 5: (a) Tensile stress-strain curves of $\mathrm{Fe}_{83} \mathrm{Ga}_{17} \mathrm{Dy}_{x}(x=0,0.05,0.1,0.2,0.4)$ alloys at room temperature; (b) Dy content $x$ dependence of ultimate tensile strength and fracture strain. The inset is the fracture specimens of $x=0$ and 0.2 alloys

Table 2: Mechanical properties of $\mathrm{Fe}_{83} \mathrm{Ga}_{17} \mathrm{Dy}_{x}(x=0,0.05,0.1,0.2,0.4)$ alloys at room temperature

\begin{tabular}{cccccc}
\hline Properties & $x=0$ & $x=0.05$ & $x=0.1$ & $x=0.2$ & $x=0.4$ \\
\hline $\begin{array}{c}\text { Ultimate tensile } \\
\text { strength (MPa) }\end{array}$ & $139 \pm 30$ & $408 \pm 15$ & $390 \pm 10$ & $209 \pm 7$ & $186 \pm 9$ \\
$\begin{array}{c}\text { Fracture strain } \\
(\%)\end{array}$ & $0.24 \pm 0.01$ & $0.91 \pm 0.03$ & $2.73 \pm 0.06$ & $11.03 \pm 0.21$ & $9.94 \pm 0.04$
\end{tabular}


enhance the ductility with $0.1<x \leq 0.4$, while the ultimate tensile strength is reduced but still higher than that of the $\mathrm{Fe}_{83} \mathrm{Ga}_{17}$ alloy.

Figure 6 demonstrates the fracture surface morphologies of $\mathrm{Fe}_{83} \mathrm{Ga}_{17} \mathrm{Dy}_{x}(x=0,0.05,0.1,0.2,0.4)$ alloys observed by SEM. From Fig. 6(a), it can be seen that the un-doped $\mathrm{Fe}_{83} \mathrm{Ga}_{17}$ alloy exhibits the feature of intergranular fracture with smooth facets, which is a typical brittle fracture indicating a severe deterioration in ductility. The small Dy addition changed the feature of intergranular fracture into transgranular cleavage for $x=0.05$ and 0.1, as shown in Fig. 6 (b and c). The fracture surfaces become rough and exhibit a river pattern. Firstly, the dispersed tiny Dy-rich precipitates in matrix [Fig. 1(b and c)] play an important role for the enhancement of ultimate tensile strength of the $x=0.05$ and 0.1 alloys. The precipitates in the matrix hinder the movement of dislocations, which leads to the improvement of ultimate tensile strength. In addition, the refinement of grains also greatly contributes to the improvement of mechanical properties. The grains are remarkably refined from $\sim 570 \mu \mathrm{m}$ for $x=0$ to $\sim 200 \mu \mathrm{m}$ for $x=0.05$ and $\sim 145 \mu \mathrm{m}$ for $x=0.1$, as shown in Figs. 1 and 2. The grain refinement hampers the movement of dislocations and causes the rising of resistance to crack propagation, which also plays an important role in the transformation of fracture mode from intergranular to transgranular. Finally, trace Dy atoms dissolved in the matrix play a role of solution strengthening, which is one of the reasons for the improvement of strength. Hence, a small addition of Dy can greatly improve the mechanical properties of as-cast $\mathrm{Fe}_{83} \mathrm{Ga}_{17}$ alloy, especially the ultimate tensile strength.
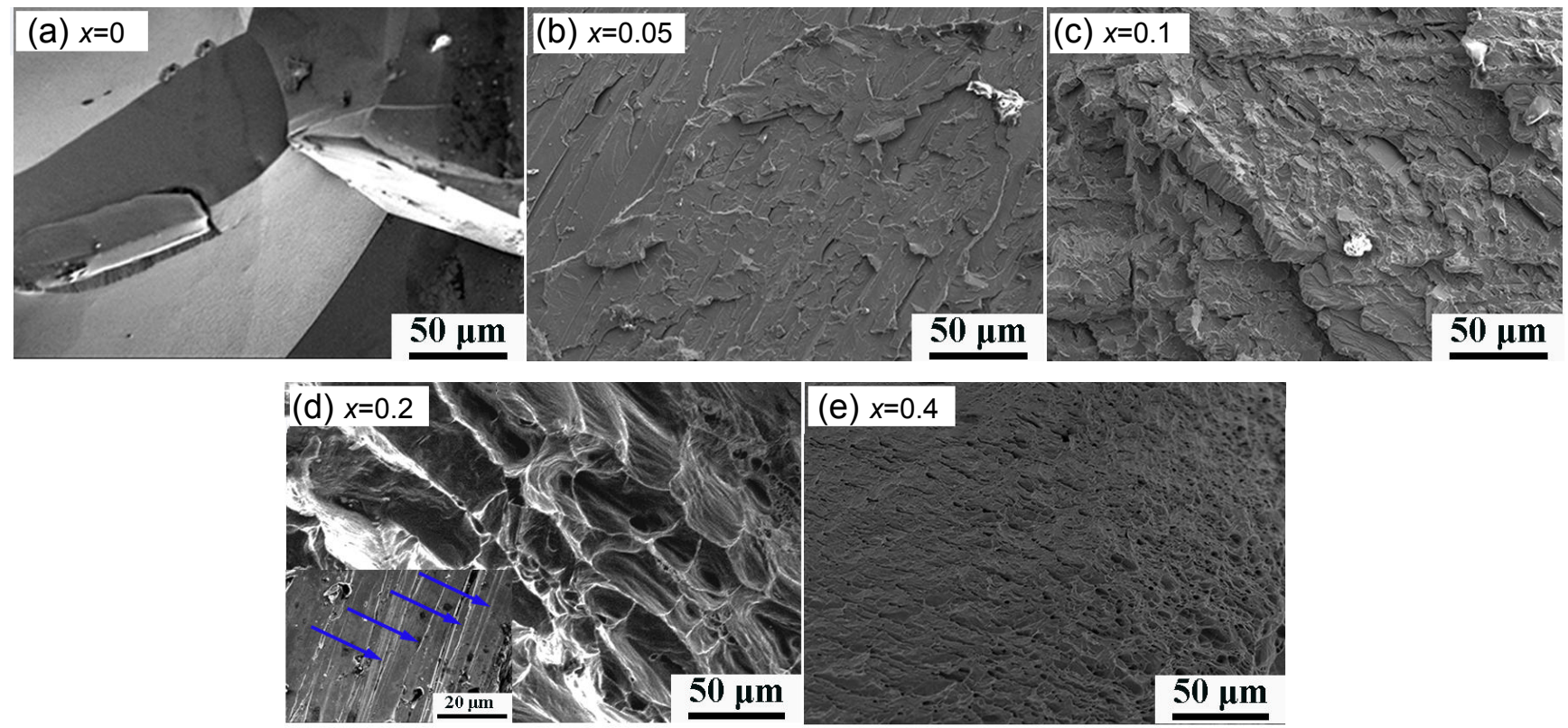

Fig. 6: Fracture surface morphologies of $\mathrm{Fe}_{83} \mathrm{Ga}_{17} \mathrm{Dy}_{\mathrm{x}}(\mathrm{x}=0,0.05,0.1,0.2,0.4)$ alloys observed by SEM. The inset is another fracture surface morphology of the $x=0.2$ alloy, and the slip bands are marked by the blue arrows

Surprisingly, the fracture mode continues to change, as the Dy content continues to increase. From Fig. 6(d), it can be seen that the fracture morphology of the $x=0.2$ alloy appears as dimple fracture, which is a typical ductile fracture. In addition, a large number of slip bands of plastic deformation are also observed with $x=0.2$, as shown in the inset of Fig. 6(d). Therefore, the tensile ductility of $x=0.2$ alloy was significantly improved with the fracture strain of $11.03 \pm 0.21 \%$. For the $x=0.4$ alloy, the similar dimple structure with the smaller size $(\sim 3 \mu \mathrm{m})$ can also be observed in Fig. 6(e), and excellent ductility is thus obtained with the fracture strain of $9.94 \pm 0.04 \%$, close to that of $x=0.2$ alloy. Overall, the enhancement in ductility of the $x=0.2$ and 0.4 alloys is due to the appearance of the dimple structure, which is associated with a large number of precipitations of the Dy-rich phase. This dimple fracture inducing a significant enhancement in ductility has been found in the previous work ${ }^{[12,41]}$. It is well known that the significant improvement in ductility may generally sacrifice the strength of the material in different extents. So the ultimate tensile strengths of the $\mathrm{Fe}_{83} \mathrm{Ga}_{17} \mathrm{Dy}_{\mathrm{x}}$
$(0.2 \leq x \leq 0.4)$ alloys are also reduced. From the above analysis, it can be concluded that fracture mode changes from intergranular fracture to transgranular cleavage and subsequently to dimple fracture with the increase of Dy addition. This transformation of the fracture mode was considered to be the reason for the evolution of mechanical behavior.

\subsection{Magnetism and magnetostriction of $\mathrm{Fe}_{83} \mathrm{Ga}_{17} \mathrm{Dy}_{x}$ alloys}

\subsubsection{Magnetism}

Figure 7(a) shows the magnetization hysteresis loops of $\mathrm{Fe}_{83} \mathrm{Ga}_{17} \mathrm{Dy}_{x}(x=0,0.05,0.1,0.2,0.4)$ alloys at room temperature, and the inset is the Dy content dependence of saturation magnetization $\left(M_{\mathrm{s}}\right)$. Figure $7(\mathrm{~b})$ is the amplified picture of Region A in Fig. 7(a). Saturation magnetization, remanent magnetization $\left(M_{\mathrm{r}}\right)$ and coercivity $\left(H_{\mathrm{c}}\right)$ for all the alloys are summarized in Table 3 . The saturation magnetization is remarkably increased by doping with Dy. The $M_{\mathrm{s}}$ of $\mathrm{Fe}_{83} \mathrm{Ga}_{17} \mathrm{Dy}_{x}(x=0,0.05,0.1,0.2,0.4)$ alloys gradually increases 
(a)

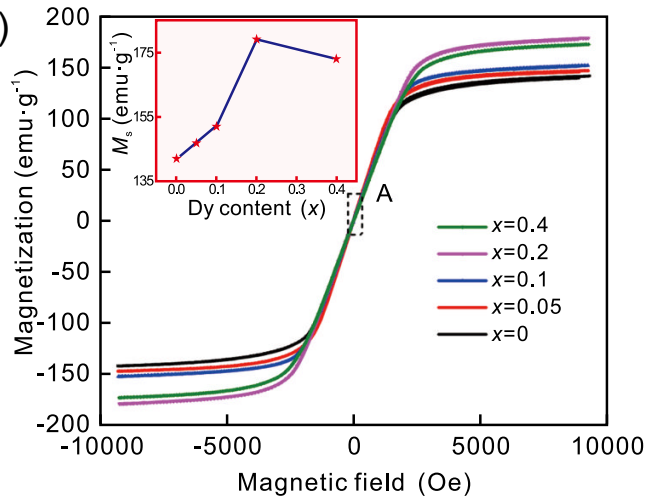

(b)

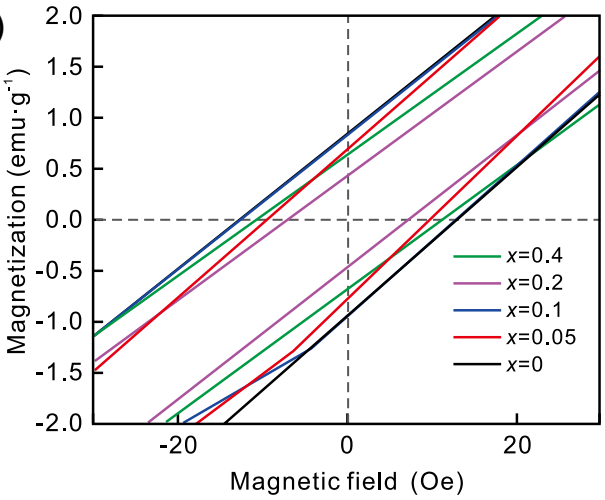

Fig. 7: (a) Magnetization hysteresis loops of $\mathrm{Fe}_{83} \mathrm{Ga}_{17} \mathrm{Dy}_{x}(x=0,0.05,0.1,0.2,0.4)$ alloys at room temperature; (b) Amplified picture of region A in Fig. 7(a). The inset is the Dy content dependence of saturation magnetization

Table 3: Saturation magnetization $\left(M_{\mathrm{s}}\right)$, remanent magnetization $\left(M_{\mathrm{r}}\right)$, coercivity $\left(H_{\mathrm{c}}\right)$ and magnetostriction of $\mathrm{Fe}_{83} \mathrm{Ga}_{17} \mathrm{Dy}_{x}$ alloys

$\begin{array}{cccccc}\text { Alloy } & x=0 & x=0.05 & x=0.1 & x=0.2 & x=0.4 \\ M_{\mathrm{s}}(\mathrm{emu} / \mathrm{g}) & 142 & 147 & 152 & 179 & 173 \\ M_{\mathrm{r}}(\mathrm{emu} / \mathrm{g}) & 0.85 & 0.71 & 0.84 & 0.42 & 0.64 \\ H_{\mathrm{c}}(\mathrm{Oe}) & 12.7 & 9.7 & 12.6 & 7.1 & 11.1 \\ \text { Magnetostriction }(\mathrm{ppm}) & 40 & 122 & 66 & 64 & 60\end{array}$

from $142 \mathrm{emu} \cdot \mathrm{g}^{-1}$ for $x=0$ to a maximum $179 \mathrm{emu} \cdot \mathrm{g}^{-1}$ for $x=0.2$, and then drops to $173 \mathrm{emu} \cdot \mathrm{g}^{-1}$ for $x=0.4$, which is still higher than that of $\mathrm{Fe}_{83} \mathrm{Ga}_{17}$ alloy. The moment of $\mathrm{Fe}_{83} \mathrm{Ga}_{17} \mathrm{Dy}_{x}$ alloys is largely dependent on the $\mathrm{Fe}$ atoms ${ }^{[27]}$. The decrease in $M_{\mathrm{s}}$ with excessive addition of Dy is mainly attributed to the reduction of Fe-Fe interactions and the precipitation of Dy-rich phase. Another important feature is that the doping of Dy in $\mathrm{Fe}_{83} \mathrm{Ga}_{17}$ alloy decreases $M_{\mathrm{r}}$ and $H_{\mathrm{c}}$, which indicates that the soft magnetic properties of the alloy are improved. When $x=0.2$, the alloy has the optimal values of $M_{\mathrm{s}}\left(179 \mathrm{emu} \cdot \mathrm{g}^{-1}\right), M_{\mathrm{r}}(0.42$ emu $\left.\cdot \mathrm{g}^{-1}\right)$ and $H_{\mathrm{c}}(7.1 \mathrm{Oe})$. Overall, the magnetic properties of the $\mathrm{Fe}_{83} \mathrm{Ga}_{17}$ alloy are appreciably improved by doping with Dy, which is mainly owing to Dy atoms entering into the A2 matrix and the precipitation of the Dy-rich phase.

\subsubsection{Magnetostriction}

Figure 8(a) shows the magnetostriction curves of as-cast $\mathrm{Fe}_{83} \mathrm{Ga}_{17} \mathrm{Dy}_{x}(x=0,0.05,0.1,0.2,0.4)$ polycrystalline alloys at room temperature. The magnetostriction of binary $\mathrm{Fe}_{83} \mathrm{Ga}_{17}$ alloy is only $40 \mathrm{ppm}$. While, the magnetostrictions of ternary alloys are improved greatly by doping with Dy. The magnetostriction of the $x=0.05$ alloy increases to $122 \mathrm{ppm}$, which is triple that of the un-doped alloy. However, the magnetostriction begins to decrease with a further increase in Dy content. The values of the magnetostriction for the $x=0.1,0.2$ and 0.4 alloys fall to 66 $\mathrm{ppm}, 64 \mathrm{ppm}$ and $60 \mathrm{ppm}$, respectively, which is still higher than that of the un-doped alloy. As it is known, the magnetostriction of FeGa alloys is determined by the lattice distortion and local strain field ${ }^{[2,42,43]}$. Previous study has found that trace $\mathrm{Tb}(0.05 \mathrm{at} . \%)$ addition to the Fe-Ga alloy improved the magnetostriction remarkably ${ }^{[3,43]}$. It is considered that a large lattice distortion introduced by trace doping $\mathrm{Tb}$ induces the enhancement of the magnetostriction. The rare earth elements Dy and $\mathrm{Tb}$ exhibit similar electronic structures and atomic radii, and both present extremely strong magnetocrystalline anisotropy. Therefore, doping of the as-cast $\mathrm{Fe}_{83} \mathrm{Ga}_{17}$ alloy with the elements Dy and $\mathrm{Tb}$ should enhance the magnetostriction and represent a similar mechanism of magnetostriction. So, the Dy content $x$ dependence of both the lattice parameter and the magnetostriction are summarized in Fig. 8(b). It can be seen that the general trend of the lattice parameter and magnetostriction is consistent. The
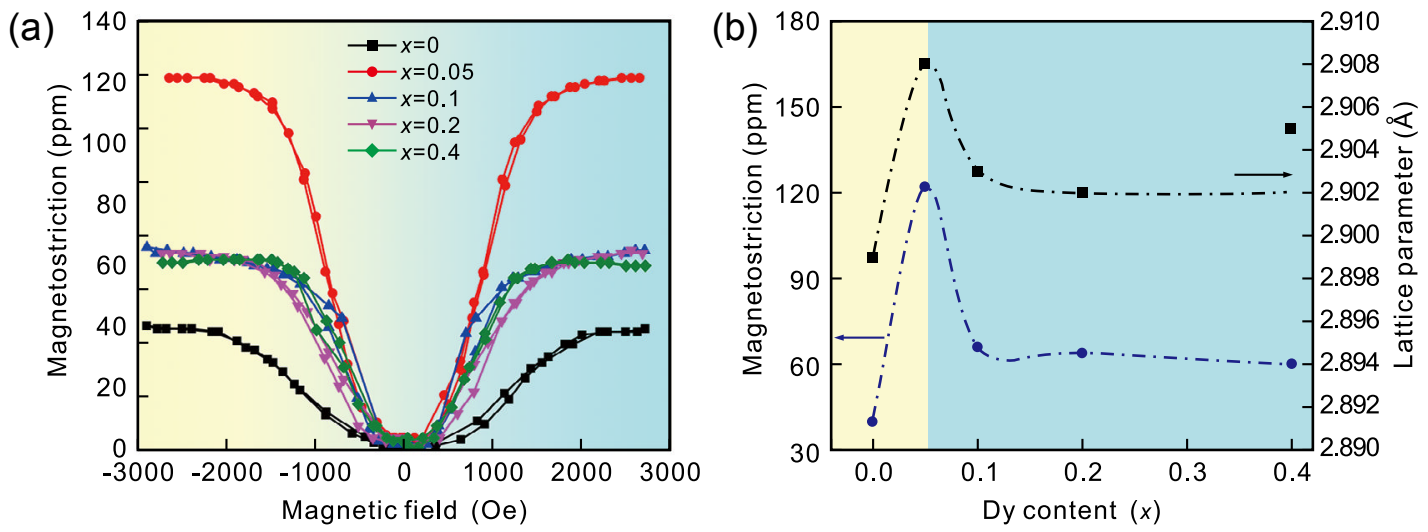

Fig. 8: (a) Magnetostriction curves of as-cast $\mathrm{Fe}_{83} \mathrm{Ga}_{17} \mathrm{Dy}_{x}(x=0,0.05,0.1,0.2,0.4)$ polycrystalline alloys at room temperature; (b) Dy content $x$ dependence of lattice parameter and magnetostriction 
abnormal change of the $x=0.4$ alloy observed in Fig. 8 (b) could be associated with a large number of precipitations of the Dyrich phase. Overall, the Dy-doped $\mathrm{Fe}_{83} \mathrm{Ga}_{17}$ alloys also show significant improvements in magnetostriction similar to Tb-doped alloys. There are good reasons to believe that trace Dy doping in FeGa alloys can introduce large lattice distortion in the matrix and induce large magnetostriction in the range of $0 \leq x \leq 0.05$, while the increase in the amount of Dy-rich precipitates has a negative impact on the magnetostrictive behavior and results in noticeable decrease in magnetostriction.

\subsection{Comprehensive comparison}

Magnetostrictive and mechanical properties of third elements or carbides doped Fe-Ga polycrystalline alloys at room temperature are summarized in Table 4. It is worth noting that $\mathrm{Fe}_{83} \mathrm{Ga}_{17} \mathrm{Dy}_{0.2}$ alloy exhibits better ductility than any other as-cast Fe-Ga polycrystalline alloy reported to date, and also demonstrates good ultimate tensile strength and magnetostriction. Doping Dy into Fe-Ga alloys provides an effective solution to the brittleness in their applications.

Table 4: Summary of magnetostrictive and mechanical properties for third elements or carbides doped Fe-Ga polycrystalline alloys at room temperature

\begin{tabular}{|c|c|c|c|c|c|}
\hline Alloy & $\begin{array}{l}\text { Preparation } \\
\text { method }\end{array}$ & $\begin{array}{c}\text { Fracture strain } \\
(\%)\end{array}$ & $\begin{array}{l}\text { Ultimate tensile } \\
\text { strength (MPa) }\end{array}$ & $\begin{array}{c}\text { Magnetostriction } \\
\text { (ppm) }\end{array}$ & References \\
\hline $\mathrm{Fe}_{83} \mathrm{Ga}_{17}$ & Arc melting & 0.2 & 139 & 40 & Current work \\
\hline $\mathrm{Fe}_{81} \mathrm{Ga}_{19}$ & Arc melting & 0.2 & 180 & 48 & Sun $A$ L et al. ${ }^{[33]}$ \\
\hline$\left(\mathrm{Fe}_{83} \mathrm{Ga}_{17}\right)_{98} \mathrm{Cr}_{2}$ & Induction melting & 0.9 & 490 & 70 & Gao X X et al. ${ }^{[44]}$ \\
\hline$\left(\mathrm{Fe}_{81} \mathrm{Ga}_{19}\right)_{99.5}(\mathrm{NbC})_{0.5}$ & Arc melting & 0.9 & 620 & 47 & Sun A L et al. ${ }^{[33]}$ \\
\hline$\left(\mathrm{Fe}_{81} \mathrm{Ga}_{19}\right)_{99}(\mathrm{TaC})_{1}$ & Arc melting & 1.0 & 625 & 60 & Sun A L et al. ${ }^{[34]}$ \\
\hline$\left(\mathrm{Fe}_{83} \mathrm{Ga}_{17}\right)_{99.8} \mathrm{~Tb}_{0.2}$ & Arc melting & 3.5 & 595 & 105 & Meng C Z et al. ${ }^{[39]}$ \\
\hline$\left(\mathrm{Fe}_{83} \mathrm{Ga}_{17}\right)_{99} \mathrm{~B}_{1}$ & Induction melting & 3.8 & 548 & 50 & Gao X X et al. ${ }^{[44]}$ \\
\hline$\left(\mathrm{Fe}_{83} \mathrm{Ga}_{17}\right)_{99.84} \mathrm{Y}_{0.16}$ & Induction melting & 4.5 & 674 & 55 & Li J H et al. ${ }^{[38]}$ \\
\hline $\mathrm{Fe}_{83} \mathrm{Ga}_{17} \mathrm{Dy}_{0.2}$ & Arc melting & 11.0 & 209 & 64 & Current work \\
\hline
\end{tabular}

\section{Conclusions}

In summary, Dy doping can improve the magnetostrictive and mechanical properties of as-cast $\mathrm{Fe}_{83} \mathrm{Ga}_{17}$ polycrystalline alloy. $\mathrm{Fe}_{83} \mathrm{Ga}_{17} \mathrm{Dy}_{0.2}$ alloy exhibits the best improved ductility with a fracture strain of $11.03 \pm 0.21 \%$, and also has the enhanced ultimate tensile strength $(209 \pm 7 \mathrm{MPa})$ and magnetostriction (64 ppm).

(1) The maximum ultimate tensile strength is obtained in the $x=0.05$ alloy with a value of $408 \pm 15 \mathrm{MPa}$, which is three times that of the un-doped $\mathrm{Fe}_{83} \mathrm{Ga}_{17}$ alloy. Dispersed tiny Dyrich precipitates in the matrix, the grain refinement, and solution strengthening are responsible for the enhancement in ultimate tensile strength at the range of $0<x \leq 0.1$. The enhancement in ductility at the range of $0.2 \leq x \leq 0.4$ is due to the appearance of the dimple structure, which is associated with a large number of precipitations of Dy-rich phase. For all the alloys, fracture mode changes from intergranular fracture to transgranular cleavage and subsequently to dimple fracture with the increase of Dy addition. This transformation of the fracture mode is considered to be the reason for the evolution of mechanical behavior.

(2) The magnetic properties of the $\mathrm{Fe}_{83} \mathrm{Ga}_{17}$ alloy is appreciably improved by doping with Dy and the optimal values of $M_{\mathrm{s}}\left(179 \mathrm{emu} \cdot \mathrm{g}^{-1}\right), M_{\mathrm{r}}\left(0.42 \mathrm{emu} \cdot \mathrm{g}^{-1}\right)$ and $H_{\mathrm{c}}(7.1 \mathrm{Oe})$ are obtained in the $x=0.2$ alloy. The improvement is mainly owing to Dy atoms entering into the $\mathrm{A} 2$ matrix and the precipitation of the Dy-rich phase.

(3) Magnetostriction is enhanced by doping Dy, and a maximum value of $122 \mathrm{ppm}$ is obtained for the $x=0.05$ alloy, which is triple that of as-cast binary $\mathrm{Fe}_{83} \mathrm{Ga}_{17}$ alloy. The improvement of magnetostriction could be attributed to the large lattice distortion induced by trace Dy doping in Fe-Ga alloys.

\section{Acknowledgments}

This work was financially supported by Beijing Science and Technology Planning Project (Grant No. Z201100006720003).

\section{References}

[1] Deng Z X, Dapino M J. Review of magnetostrictive vibration energy harvesters. Smart Mater. Struct., 2017, 26: 103001.

[2] Atulasimha J, Flatau A B. A review of magnetostrictive irongallium alloys. Smart Mater. Struct., 2011, 20: 043001.

[3] Kellogg R A, Russell A M, Lograsso T A, et al. Tensile properties of magnetostrictive iron-gallium alloys. Acta Mater., 2004, 52: 5043-5050.

[4] Guruswamy S, Srisukhumbowornchai N, Clark A E, et al. Strong, ductile, and low-field-magnetostrictive alloys based on Fe-Ga. Scr. Mater., 2000, 43: 239-244.

[5] Wang N J, Liu Y, Zhang $\mathrm{H} \mathrm{W}$, et al. Fabrication, magnetostriction properties and applications of Tb-Dy-Fe alloys: A review. China Foundry, 2016, 13: 75-84. 
[6] Clark A E. Magnetic and magnetoelastic properties of highly magnetostrictive rare earth-iron laves phase compounds. AIP Conf. Proc., 1974, 18: 1015-1029.

[7] Wang $\mathrm{N} \mathrm{J}$, Liu Y, Zhang $\mathrm{H} \mathrm{W}$, et al. Effect of $\mathrm{Co}, \mathrm{Cu}, \mathrm{Nb}, \mathrm{Ti}$, $\mathrm{V}$ on magnetostriction and mechanical properties of $\mathrm{TbDyFe}$ alloys. Intermetallics, 2018, 100: 188-192.

[8] Summers E M, Lograsso T A, Wun-Fogle M. Magnetostriction of binary and ternary Fe-Ga alloys. J. Mater. Sci., 2007, 42: 9582-9594.

[9] Na S M, Flatau A B. Deformation behavior and magnetostriction of polycrystalline $\mathrm{Fe}-\mathrm{Ga}-\mathrm{X}(\mathrm{X}=\mathrm{B}, \mathrm{C}, \mathrm{Mn}, \mathrm{Mo}, \mathrm{Nb}, \mathrm{NbC}$ ) alloys. J. Appl. Phys., 2008, 103: 07D304.

[10] Sun A L, Liu J H, Jiang C B. Recrystallization, texture evolution, and magnetostriction behavior of rolled $\left(\mathrm{Fe}_{81} \mathrm{Ga}_{19}\right)_{98} \mathrm{~B}_{2}$ sheets during low-to-high temperature heat treatments. J. Mater. Sci., 2014, 49: 4565-4575.

[11] Li J H, Gao X X, Zhu J, et al. Texture evolution and magnetostriction in rolled $\left(\mathrm{Fe}_{81} \mathrm{Ga}_{19}\right)_{99} \mathrm{Nb}_{1}$ alloy. J. Alloys Compd., 2009, 476: 529-533.

[12] Li J H, Gao XX, Zhu J, et al. Ductility, texture and large magnetostriction of Fe-Ga-based sheets. Scr. Mater., 2010 63: $246-249$.

[13] Restorff J B, Wun-Fogle M, Hathaway K B, et al. Tetragona magnetostriction and magnetoelastic coupling in Fe-Al, Fe-Ga, $\mathrm{Fe}-\mathrm{Ge}$, Fe-Si, Fe-Ga-Al, and Fe-Ga-Ge alloys. J. Appl. Phys., 2012, 111: 023905.

[14] Restorff J B, Wun-Fogle M, Clark A E, et al. Magnetostriction of ternary Fe-Ga-X alloys (X=Ni,Mo,Sn,Al). J. Appl. Phys., 2002, 91: 8225-8227.

[15] Huang M, Lograsso T A, Clark A E, et al. Effect of interstitia additions on magnetostriction in Fe-Ga alloys. J. Appl. Phys., 2008, 103: 07b314.

[16] Huang M, Du Y, Mcqueeney R J, et al. Effect of carbon addition on the single crystalline magnetostriction of $\mathrm{Fe}-\mathrm{X}(\mathrm{X}=$ Al and Ga) alloys. J. Appl. Phys., 2010, 107: 053520.

[17] Li J H, Gao X X, Zhu J, et al. Ductility enhancement and magnetostriction of polycrystalline $\mathrm{Fe}-\mathrm{Ga}$ based alloys. J. Alloys Compd., 2009, 484: 203-206.

[18] Mungsantisuk P, Corson R P, Guruswamy S. Influence of Be and $\mathrm{Al}$ on the magnetostrictive behavior of FeGa alloys. J. Appl. Phys., 2005, 98: 123907.

[19] Lograsso T A, Jones N J, Schlagel D L, et al. Effects of Zn additions to highly magnetoelastic FeGa alloys. J. Appl. Phys., 2015, 117: 17e701.

[20] Clark A E, Restorff J B, Wun-Fogle M, et al. Magnetostriction of ternary Fe-Ga-X ( $\mathrm{X}=\mathrm{C}, \mathrm{V}, \mathrm{Cr}, \mathrm{Mn}, \mathrm{Co}, \mathrm{Rh})$ alloys. J. Appl. Phys., 2007, 101: 09C507.

[21] Bormio-Nunes $\mathrm{C}$, Sato Turtelli R, Mueller $\mathrm{H}$, et al. Magnetostriction and structural characterization of $\mathrm{Fe}-\mathrm{Ga}-\mathrm{X}(\mathrm{X}=\mathrm{Co}, \mathrm{Ni}, \mathrm{Al})$ moldcast bulk. J. Magn. Magn. Mater., 2005, 290-291: 820-822.

[22] Han $Y$ J, Wang $H$, Zhang $T L$, et al. Exploring structural origin of the enhanced magnetostriction in Tb-doped $\mathrm{Fe}_{83} \mathrm{Ga}_{17}$ ribbons: Tuning Tb solubility. Scr. Mater., 2018, 150: 101-105.

[23] Jiang L P, Yang J D, Hao H B, et al. Giant enhancement in the magnetostrictive effect of $\mathrm{FeGa}$ alloys doped with low levels of terbium. Appl. Phys. Lett., 2013, 102: 222409.

[24] Xiao X M, Gao X X, Li J H, et al. Influence of yttrium on the structure and magnetostriction of $\mathrm{Fe}_{83} \mathrm{Ga}_{17}$ alloy. Int. J. Min. Met. Mater., 2012, 19: 849-855.
[25] Yao Z Q, Tian X, Jiang L P, et al. Influences of rare earth element Ce-doping and melt-spinning on microstructure and magnetostriction of $\mathrm{Fe}_{83} \mathrm{Ga}_{17}$ alloy. J. Alloys Compd., 2015, 637: 431-435.

[26] He Y K, Jiang C B, Wu W, et al. Giant heterogeneous magnetostriction in Fe-Ga alloys: Effect of trace element doping. Acta Mater., 2016, 109: 177-186.

[27] Wu W, Jiang C B. Improved magnetostriction of $\mathrm{Fe}_{83} \mathrm{Ga}_{17}$ ribbons doped with Sm. Rare Met., 2016, 36: 18-22.

[28] Zhou T D, Zhang Y, Luan D C, et al. Effect of cerium on structure, magnetism and magnetostriction of $\mathrm{Fe}_{81} \mathrm{Ga}_{19}$ alloy. J. Rare Earths., 2018, 36: 721-724.

[29] Wu Y Y, Chen Y J, Meng C Z, et al. Multiscale influence of trace $\mathrm{Tb}$ addition on the magnetostriction and ductility of $\langle 100\rangle$ oriented directionally solidified Fe-Ga crystals. Phys. Rev. Mater., 2019, 3: 033401.

[30] Emdadi A, Palacheva V V, Balagurov A M, et al. Tb-dependent phase transitions in Fe-Ga functional alloys. Intermetallics, 2018, 93: 55-62.

[31] Barua R, Taheri $P$, Chen $Y$, et al. Giant enhancement of magnetostrictive response in directionally-solidified $\mathrm{Fe}_{83} \mathrm{Ga}_{17} \mathrm{Erx}$ compounds. Materials, 2018, 11: 1039.

[32] Nolting A E, Summers E. Tensile properties of binary and alloyed Galfenol. J. Mater. Sci., 2015, 50: 5136-5144.

[33] Sun A L, Liu J H, Jiang C B. Microstructural characteristics and in situ reinforcement in $\mathrm{NbC}$-doped $\mathrm{Fe}_{81} \mathrm{Ga}_{19}$ magnetostrictive alloys. Mater. Des., 2015, 88: 1342-1346.

[34] Sun A L, Liu J H, Jiang C B. Dual-reinforcement (TaCparticle+TaCdendrite)/FeGa magnetostrictive composites. Mater. Sci. Eng. A, 2015, 639: 370-373.

[35] Li J H, Zhang W L, Yuan C, et al. Inhibition force of precipitates for promoting abnormal grain growth in magnetostrictive $\mathrm{Fe}_{83} \mathrm{Ga}_{17}-(\mathrm{B}, \mathrm{NbC})$ alloy sheets. Rare. Met., 2017, 36: 886-893.

[36] Na S M, Atwater K M, Flatau A B. Particle pinning force thresholds for promoting abnormal grain growth in magnetostrictive $\mathrm{Fe}-\mathrm{Ga}$ alloy sheets. Scr. Mater., 2015, 100: 1-4.

[37] Takahashi T, Okazaki T, Furuya Y. Improvement in the mechanical strength of magnetostrictive (Fe-Ga-Al)-X-C ( $\mathrm{X}=\mathrm{Zr}, \mathrm{Nb}$ and $\mathrm{Mo})$ alloys by carbide precipitation. Scr. Mater., 2009, 61: 5-7.

[38] Li J H, Xiao X M, Yuan C, et al. Effect of yttrium on the mechanical and magnetostrictive properties of $\mathrm{Fe}_{83} \mathrm{Ga}_{17}$ alloy. J. Rare Earths., 2015, 33: 1087-1092.

[39] Meng C Z, Wang H, Wu Y Z, et al. Investigating enhanced mechanical properties in dual-phase $\mathrm{Fe}-\mathrm{Ga}-\mathrm{Tb}$ alloys. Sci. Rep., 2016, 6: 34258.

[40] Golovin I S, Balagurov A M, Palacheva V V, et al. Influence of $\mathrm{Tb}$ on structure and properties of $\mathrm{Fe}-19 \% \mathrm{Ga}$ and $\mathrm{Fe}-27 \% \mathrm{Ga}$ alloys. J. Alloys Compd., 2017, 707: 51-56.

[41] Hu X F, Du Y B, Yan D S, et al. Effect of Cu content on microstructure and properties of $\mathrm{Fe}-16 \mathrm{Cr}-2.5 \mathrm{Mo}$ damping alloy. J. Mater. Sci. Technol., 2018, 34: 774-781.

[42] Meng C Z, Jiang C B. Magnetostriction of a $\mathrm{Fe}_{83} \mathrm{Ga}_{17}$ single crystal slightly doped with Tb. Scr. Mater., 2016, 114: 9-12.

[43] Wu Y Y, Fang L, Meng C Z, et al. Improved magneostriction and mechanical properties in dual-phase FeGa single crystal. Mater. Res. Lett., 2018, 6: 327-332.

[44] Gao X X, Li J H, Zhu J, et al. Effect of B and Cr on mechanical properties and magnetostriction of iron-gallium alloy. Mater. Trans., 2009, 50: 1959-1963. 